Subscriber access provided by Lib4RI - Library for Eawag, Empa, PSI \& WSL

\title{
Article
}

\section{D imaging of nanoparticles in an inorganic matrix using TOF-SIMS validated with STEM and EDX}

Agnieszka Priebe, Jean-Paul Barnes, Thomas Edward James

Edwards, Laszlo Pethö, István Balogh, and Johann Michler

Anal. Chem., Just Accepted Manuscript • DOI: 10.1021/acs.analchem.9b02545 • Publication Date (Web): 20 Aug 2019

Downloaded from pubs.acs.org on August 27, 2019

\section{Just Accepted}

"Just Accepted" manuscripts have been peer-reviewed and accepted for publication. They are posted online prior to technical editing, formatting for publication and author proofing. The American Chemical Society provides "Just Accepted" as a service to the research community to expedite the dissemination of scientific material as soon as possible after acceptance. "Just Accepted" manuscripts appear in full in PDF format accompanied by an HTML abstract. "Just Accepted" manuscripts have been fully peer reviewed, but should not be considered the official version of record. They are citable by the Digital Object Identifier (DOI®). "Just Accepted" is an optional service offered to authors. Therefore, the "Just Accepted" Web site may not include all articles that will be published in the journal. After a manuscript is technically edited and formatted, it will be removed from the "Just Accepted" Web site and published as an ASAP article. Note that technical editing may introduce minor changes to the manuscript text and/or graphics which could affect content, and all legal disclaimers and ethical guidelines that apply to the journal pertain. ACS cannot be held responsible for errors or consequences arising from the use of information contained in these "Just Accepted" manuscripts. 


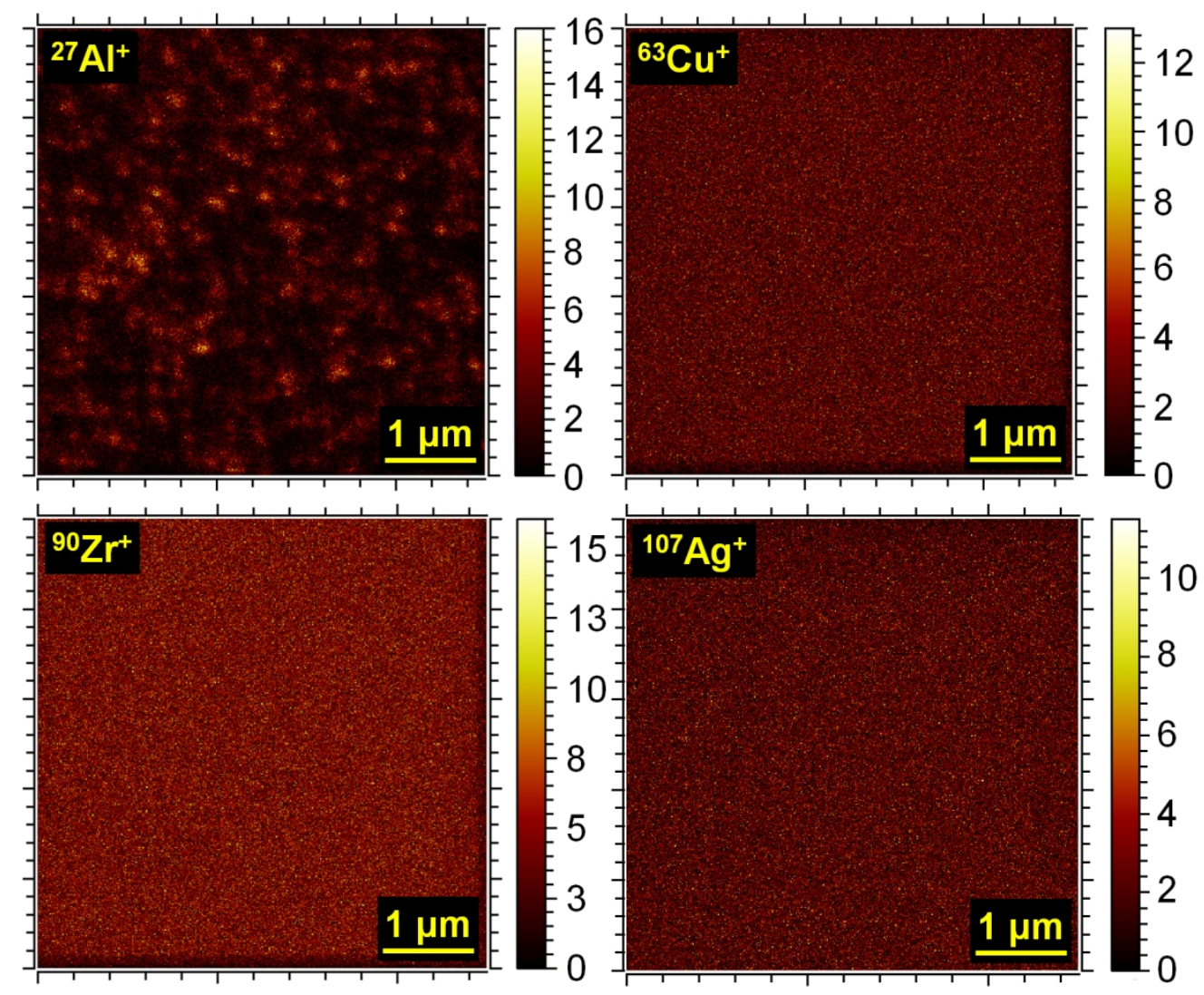

Figure 1. Elemental structure of ZrCuAg+Alnp nanocomposite obtained with a $60 \mathrm{keV}$ Bi32+ beam (signal integration over 20 scans). No binning.

$141 \times 116 \mathrm{~mm}(300 \times 300 \mathrm{DPI})$ 
a)

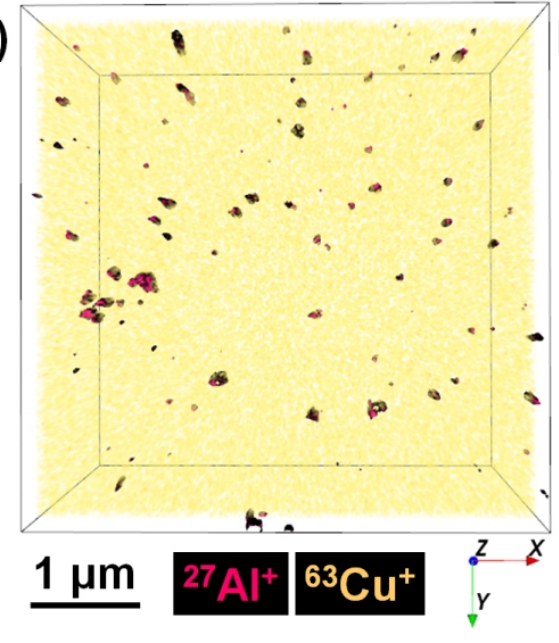

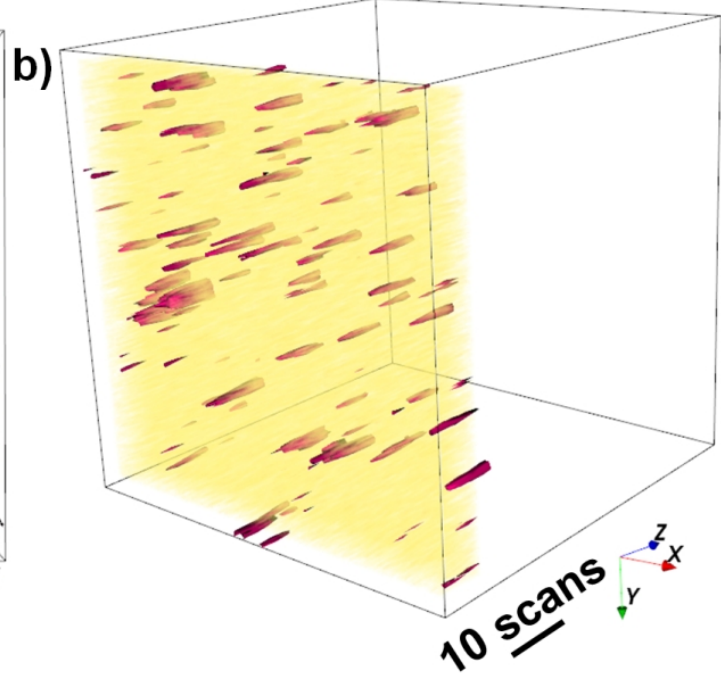

Figure 2. Overlay of $27 \mathrm{Al}+$ signal (magenta) iso-surface (median filter with the kernel size $=3$ and the isovalue of $18.9 \%$ ) and $63 \mathrm{Cu}+$ signal (yellow) measured with the TOF.SIMS5. Xy binning: 4, binning in z: 2 , visualization over 9 scans. a) a front view, b) a side view. A z-axis is given in time units. The data was cropped in $\mathrm{z}$ to visualize better the Al nanoparticles.

$$
129 \times 68 \mathrm{~mm}(300 \times 300 \text { DPI) }
$$



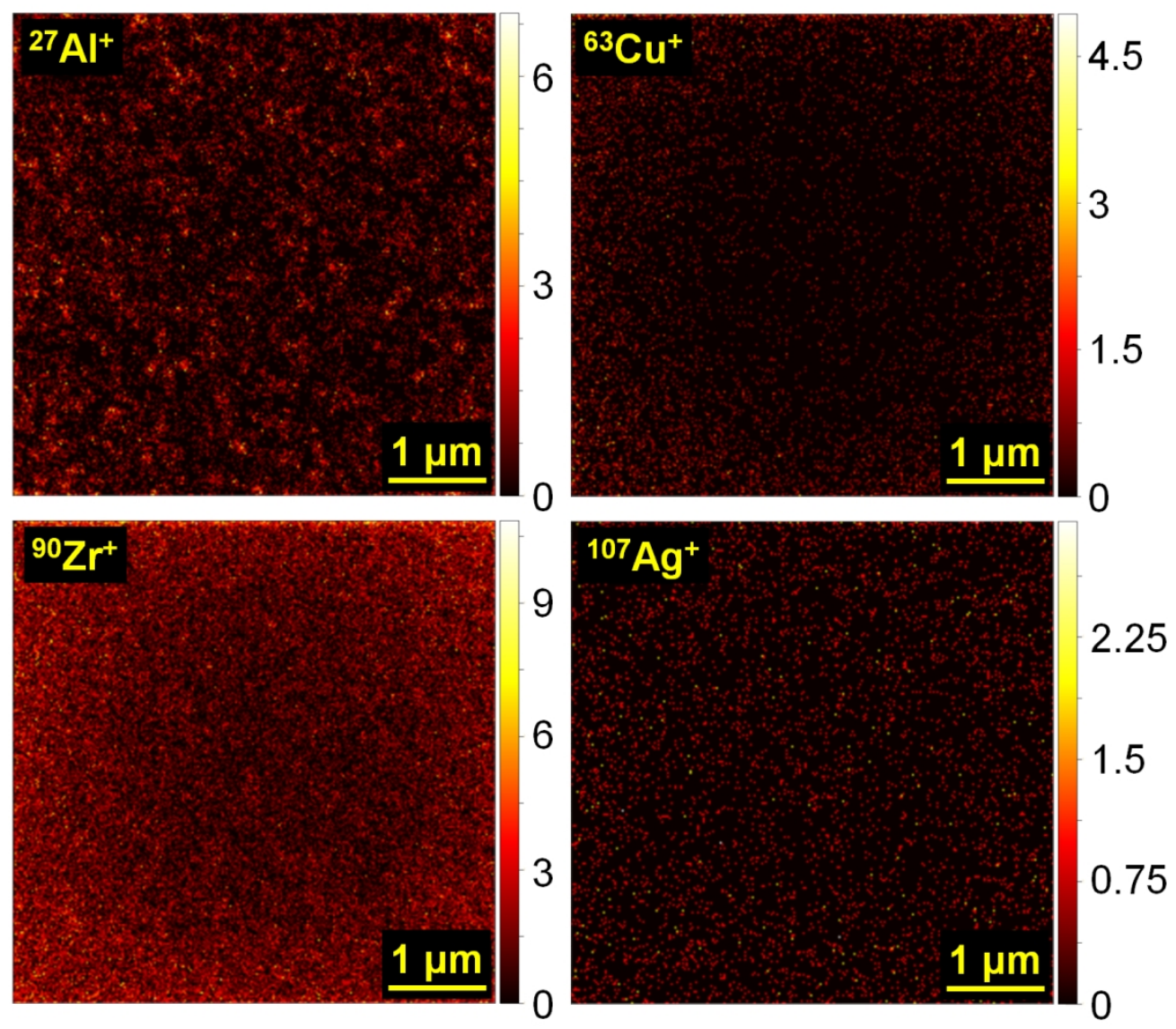

Figure 3. Elemental structure of ZrCuAg+Alnp nanocomposite obtained with a $30 \mathrm{keV} \mathrm{Ga+} \mathrm{beam} \mathrm{(signal}$ integration over 190 scans).

$130 \times 113 \mathrm{~mm}(300 \times 300 \mathrm{DPI})$ 

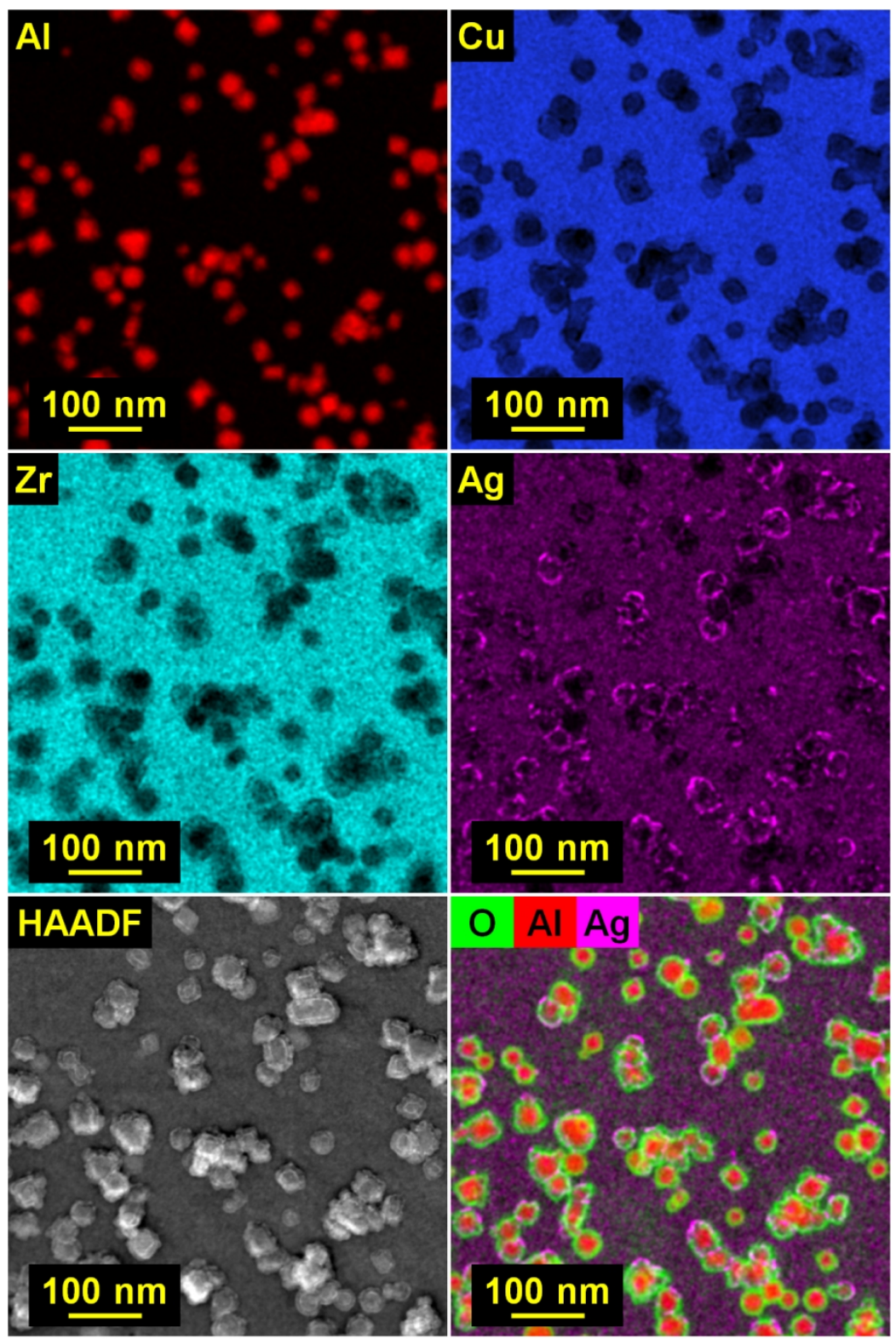

Figure 4. STEM-HAADF and STEM-EDX (at \%) images of a $50 \mathrm{~nm}$ thick layer of ZrCuAg+Alnp. In the colour maps, the scale is such that the quantity of material increases in tone from black (the lowest values) to the given colour (the highest values).

$108 \times 162 \mathrm{~mm}(300 \times 300 \mathrm{DPI})$ 
The importance of nanocomposites 1,2 has dramatically increased in the last decades due to their extraordinary properties that are very often unprecedented at the macroscale. For example, recently developed Bulk Metallic Glasses (BMG) ${ }^{3-7}$ are amorphous alloys that have excellent mechanical properties, such as high hardness, but at the same time do not deform plastically and therefore become brittle under exposure to external stress. However, propagation of cracks and shear bands 8,9 can be hampered by introducing nanoparticles ${ }^{10}$. This can broaden the application scope of these new materials. The response of the nanocomposite's matrix can vary depending on the type and size of nanoparticles as well as their distribution in a threedimensional (3D) space. Thus the advances in designing and fabricating new nanomaterials impose a strong demand for pushing characterization techniques to their physical limits. Atom Probe Tomography (APT) ${ }^{11-15}$ and Transmission Electron Microscopy (TEM) ${ }^{16,17}$ provide precise information on elemental structure with high spatial resolution of around $0.1 \mathrm{~nm}{ }^{18-20}$. However, a typical sample size does not exceed $100 \mathrm{~nm}{ }^{21}$. Such a small volume can describe only a local variation in material composition but not necessarily be representative of the entire specimen. Moreover, those techniques require complex and time-consuming sample preparation using a Focused Ion Beam (FIB) ${ }^{22-25}$. An excellent alternative to APT and TEM is TOF-SIMS (Time-ofFlight Secondary Ion Mass Spectrometry) ${ }^{26,27}$ which allows the elemental composition to be characterized in a $3 \mathrm{D}$ volume with high lateral resolution $<20 \mathrm{~nm}{ }^{28,29}$ and depth resolution $<1 \mathrm{~nm}{ }^{30}$ over a Region-of-Interest (ROI) defined by the FIB raster area, usually from $1 \mu \mathrm{m} \times 1 \mu \mathrm{m}$ up to $400 \mu \mathrm{m} \times 400$ $\mu \mathrm{m}$. The TOF-SIMS signal magnitude is determined by ion yields (i.e. a fraction of ionized species of the entire sputtered population) of sample components which depend not only on a primary beam (an ion type and a beam type, i.e. a mono- or poly-atomic beam) but also on the element interaction with neighboring atoms/molecules (so-called matrix effect ${ }^{27}$ ). Therefore, it can span over several orders of magnitude, making this technique non-quantitative. Nevertheless, the TOF-SIMS technique has significant advantages over other elemental characterization methods. First of all, it has capability of detecting all ion types (i.e. light and heavy ions) including isotope recognition whilst, for example, the method combining a FIB slicing with SEM-EDX (Energy-dispersive $\mathrm{X}$-ray spectroscopy) is not suitable for studying light elements. Moreover, the SEM-EDX technique has lower spatial resolution than TOF-SIMS as the signal is acquired from the interaction volume of $\sim 1 \mu \mathrm{m}^{3}{ }^{31}$. Comparing APT and TEM with TOF-SIMS, in the latter case relatively large specimens with dimensions of several tens of micrometers can be measured with nanoscale resolution ${ }^{32}$. Moreover, thanks to the wide range of ROI size, a sample structure can be studied globally (for example to study thick functional layers) and locally (for example to detect precipitations). In addition, TOF-SIMS does not require any particular sample preparation prior a measurement. However, due to potential topology effects ${ }^{33-35}$, samples should preferable be flat.

Several studies ${ }^{28,29,36-38}$ have shown the feasibility of measuring very thin (hundreds to tens of nanometers thick) layers using TOF-SIMS. Nevertheless, in those cases the 
acquired signals are integrated over relatively large volumes. Besides that, up to now only 2D imaging of $50 \mathrm{~nm} \mathrm{Ag}$ nanoparticles present in a Madin-Darby Canine Kidney was successfully performed ${ }^{28}$. As presented in ${ }^{39}$, the attempts to image Ag nanoparticles incorporated into biological cells in 3D were unsuccessful due to different sputtering rates of organic and inorganic components. Moreover the authors encountered problems with low Ag signals obtained with an Ar-cluster and an $\mathrm{O}_{2}{ }^{+}$sputter beams. Another literature ${ }^{40}$ reports TOF-SIMS measurements on $70 \mathrm{~nm} \quad \mathrm{TiO}_{2}$ nanoparticles. In the case of nanoparticles deposited on a polymer a $2 \mathrm{D}$ elemental image of $\mathrm{Ti}^{+}+\mathrm{TiO}^{+}$signals was obtained. Nevertheless, studying the $\mathrm{TiO}_{2}$ nanoparticles incorporated into an algal biofilm did not allow a $\mathrm{TiO}^{+}$signal to be represented in 3D together with organic components signals due to the applied negative ion detection mode. Thus, the authors used Ti-containing negative secondary ions to localize indirectly the location on nanoparticles. The TOFSIMS technique was also used for 3D imaging of polymer nanoparticles in HeLa cells ${ }^{41}$. Due to the used spatial resolution of $\approx 1 \mu \mathrm{m}$ probably only clusters of nanoparticles were detected. In addition, there are suspects that a part of the signals used for nanoparticle representation originated from the cell. However, to our best knowledge no studies have reported observation of isolated single inorganic nanoparticles in monolithic inorganic materials in 3D space.

In this work, for the first time we highlight the TOF-SIMS capability of spatially resolving and representing in a 3D space tens of nanometer large metallic nanoparticles embedded in an alloy matrix. In order to prove that, we have designed a model sample based on a $\mathrm{ZrCuAg} \mathrm{BMG}$ and Al nano-filler. The TOF-SIMS data obtained with two very different instruments (i.e. a dedicated dual-beam instrument from IONTOF using a pulsed bismuth analysis beam and an oxygen sputtering beam as well as a TOF detector from TOFWERK used as an add-on to a commercial FIB-SEM system in which a gallium beam is used for both sputtering and imaging) was validated with STEM (Scanning TEM) images as well as EDX elemental maps.

\section{EXPERIMENTAL}

\section{Materials}

A novel BMG-based nanocomposite (an inorganic-inorganic hybrid material) was designed and fabricated at Empa. The microstructure consisted of tens of nanometres diameter light element $\left({ }^{27} \mathrm{Al}\right)$ nanoparticles incorporated into a matrix composed of heavy elements, i.e. ${ }^{63} \mathrm{Cu},{ }^{90} \mathrm{Zr}$ and ${ }^{107} \mathrm{Ag}$. This has provided a very strong mass contrast allowing an effect of mass interference to be reduced or even prevented and therefore better element recognition. Moreover, since the nanoparticles constituted only a small fraction of a nanocomposite structure, they had to be characterized by a high ion yield in order to be detected with the TOF-SIMS technique. Thus Al, having two orders of magnitude lower detection limit $\left(3 \cdot 10^{8}\right.$ atoms $\left.\cdot \mathrm{cm}^{-2}\right)$ than $\mathrm{Cu}\left(1 \cdot 10^{10}\right.$ atoms $\cdot \mathrm{cm}^{-2}$ ${ }^{42}$ ) was chosen as a perfect candidate. Also the amorphous structure of the BMG alloy $(\mathrm{ZrCuAg})$ prevents preferential primary ion beam sputtering within the matrix. A $100 \mathrm{~nm}$ nanocomposite thin film was deposited on a Si substrate using the Physical Vapour Deposition (PVD) technique ${ }^{43}$. A custom-made instrument with a $5.4 \cdot 10^{-8}$ mbar base pressure provided by MANTIS Deposition Ltd (Oxfordshire, United Kingdom) comprised of a 3"' sputter magnetron and a NanoGen50 nanoparticle generator was used. The sputtering target $\mathrm{ZrCuAg}$ alloy (45 atm\% $\mathrm{Zr}, 45.5 \mathrm{~atm} \% \mathrm{Cu}$ and 9.5 atm $\%$ Ag, manufactured by Plasmamaterials, Inc. Livermore, CA, USA) was bombarded with Ar plasma generated at 35 $\mathrm{mA}$ DC electric current and at a $2.7 \cdot 10^{-3}$ mbar process pressure. The Al nanoparticles were co-deposited from an $\mathrm{Al}$ target (99.999\% purity, manufactured by EVOCHEM Advanced Materials GmbH, Offenbach am Main, Germany) at $100 \mathrm{~mA}$ DC electric current.

The TEM measurements in scanning mode were performed on the same material type but deposited with a thickness of 50 $\mathrm{nm}$ on a holey carbon film on a $\mathrm{Cu}$ grid.

Finally, a pure $100 \mathrm{~nm}$ thick layer of pure Al was deposited on a Si substrate. This sample was measured in a TOF-SIMS depth profile mode to calculate an Al useful yield and subsequently to estimate a minimum size of $\mathrm{Al}$ nanoparticles that can still be detected with the TOF-SIMS technique.

\section{Methods}

An elemental structure of the $\mathrm{ZrCuAg}+\mathrm{Al}_{\text {np }}$ nanocomposite in a $3 \mathrm{D}$ space was measured using a dedicated dual beam system TOF.SIMS 5 from IONTOF (Munich, Germany) that operates in Ultra-High Vacuum (UHV) conditions. An $80 \mathrm{nA}$ oxygen beam at $500 \mathrm{eV}$ energy was used for sputtering and a $0.11 \mathrm{pA} \mathrm{Bi}_{3}{ }^{2+}$ LMIG (Liquid Metal Ion Gun) beam at $60 \mathrm{keV}$ energy was used for imaging. Both primary beams were pulsed and the data was acquired in a repetitive sequence of three subsequent steps: 1) analysing 1 frame, 2) sputtering for $10 \mathrm{~s}$ and 3) pause of $1 \mathrm{~s}$. The sputter beam and the analysis beam were positioned at $45^{\circ}$ angle with respect to the sample normal and orthogonally with respect to each other (as shown in ${ }^{44}$ ). Additionally, oxygen flooding at a partial pressure of $4 \cdot 10^{-6}$ mbar was used in order to enhance positive ion yields 2745 and therefore the magnitude of TOF-SIMS signals. The data was acquired from a $5 \mu \mathrm{m} \times 5 \mu \mathrm{m}$ raster area with 10 shots pixel $^{-1}, 60 \mu$ s cycle time. Each image consisted of a $512 \times 512$ pixel array. Taking into account signal integration over 20 scans, this means that the ROI was exposed to a dose of $1.08 \cdot 10^{9}$ ions (i.e. a dose density of $4.32 \cdot 10^{15}$ ions $\cdot \mathrm{cm}^{-2}$ ). The mass calibration was performed using the majority elements of the sample, i.e. ${ }^{27} \mathrm{Al},{ }^{63} \mathrm{Cu}$ and ${ }^{90} \mathrm{Zr}$. The stack of acquired scans was laterally shift-corrected.

The experiments were repeated with a High Vacuum (HV) Compact TOF (CTOF) from TOFWERK (Thun, Switzerland). This detector was used as an add-on to a multi-analytical instrument LYRA3 from Tescan (Brno, Czech Republic) that comprises of a FIB and a SEM. A continuous (not pulsed) 30 $\mathrm{keV}$ mono-isotopic ${ }^{69} \mathrm{Ga}^{+}$beam was used for both sputtering and analysis. The measurements were conducted at $15 \mathrm{pA}$ ion current, $50 \mu \mathrm{m}$ aperture and $10 \mu \mathrm{s}$ dwell time. The scan area and resolution were the same as during the previous experiment but $2 \times 2$ binning was applied (due to software constraints). In this case 190 scans were used for the data representation so the corresponding dose was as high as $4.66 \cdot 10^{10}$ ions (i.e. dose density of $1.87 \cdot 10^{17}$ ions $\cdot \mathrm{cm}^{-2}$ ). The 
specimen was mounted perpendicularly to the FIB and at the coincidence point between the FIB and the electron beam. In this case no additional gases were used during data acquisition.

The exact size of the $\mathrm{Al}$ nanoparticles was measured using a Titan Themis TEM from FEI (Hillsboro, Oregon, USA). The High-Angle Annular Dark-Field (HAADF) images (1.5 nm pixel size) from $66-200$ mrad range were acquired at 200 $\mathrm{keV}$ energy electron beam operated in STEM mode. TEMEDX maps showing the elemental composition of the sample were obtained using a SuperEDX system at $5.3 \mathrm{nA}$ and $5 \mu \mathrm{s}$ dwell time from an area of $618 \mathrm{~nm} \times 618 \mathrm{~nm}$ as a series of 1264 drift-corrected and integrated frames.

\section{RESULTS AND DISCUSSION}

\section{Detection of nanoparticles using TOF-SIMS}

The minimum Ga FIB spot size can be as small as $2.5 \mathrm{~nm}$ 46,47. However, this can be obtained by using $1 \mathrm{pA}$ beam current which, in general, is too low to find an application in the TOF-SIMS elemental characterization. Therefore in practice, higher Ga ion currents resulting in lower spatial resolution are used. This implies that observing small objects, such as nanoparticles, with the TOF-SIMS technique is a challenging task due to their size which is of the order of the primary ion beam diameter or even smaller. Consequently, limitations on the lateral resolution are imposed since the obtained image results from a convolution of an object shape with the imaging beam shape ${ }^{38}$. Moreover, in this situation a TOF-SIMS signal is acquired from a very small volume which means that the quantity of material forming a nanoparticle can be insufficient to give a signal high enough to spatially resolve individual nanoparticles (although an integrated signal of all nanoparticles within a ROI can still be detected and observed in a mass spectrum).

In Figure 1 , the $\mathrm{ZrCuAg}+\mathrm{Al}_{\text {np }}$ elemental structure obtained with a $60 \mathrm{keV}$ pulsed $\mathrm{Bi}_{3}{ }^{2+}$ imaging beam is presented. In contrast to homogenously distributed signals of the matrix elements $\left({ }^{63} \mathrm{Cu}^{+},{ }^{90} \mathrm{Zr}^{+}\right.$and $\left.{ }^{107} \mathrm{Ag}^{+}\right)$, a dense concentration of regions with significantly increased ${ }^{27} \mathrm{Al}^{+}$signal was observed. These signal variations in the lateral plane can indicate measurements of single Al nanoparticles or their clusters. Agglomerations of nanoparticles can be distinguished in 3D space by applying visualization thresholds on a reconstructed representation of the ${ }^{27} \mathrm{Al}^{+}$signal overlaid with the ${ }^{63} \mathrm{Cu}^{+}$signal (Figure 2). A median filter with a kernel size of 3 and an isovalue of $18.9 \%$ (adjusted individually for ${ }^{27} \mathrm{Al}^{+}$) was applied. This means that the signals lower than this value were filtered and, thus, not displayed on the image. The dimensions in $z$ directions are given in number of frames corresponding to the data acquisition time. In the case of non-standard materials (such as the novel nanocomposites studied in this work), when sputtering rates are unknown, these values cannot be simply recalculated into space units (i.e. for example $\mathrm{nm}$ ) unless an entire film of a known thickness is sputtered. Although in the next step of these studies a pure $100 \mathrm{~nm}$ thick $\mathrm{Al}$ thin film was completely sputtered to calculate $\mathrm{Al}$ useful yield, $\mathrm{Al}$ sputter rate cannot be used for $z$-dimension estimates of the $\mathrm{ZrCuAg}+\mathrm{Al}_{\text {np }}$ as $\mathrm{Al}$ constitutes only a fraction of the nanocomposite and the presence of heavy elements such as

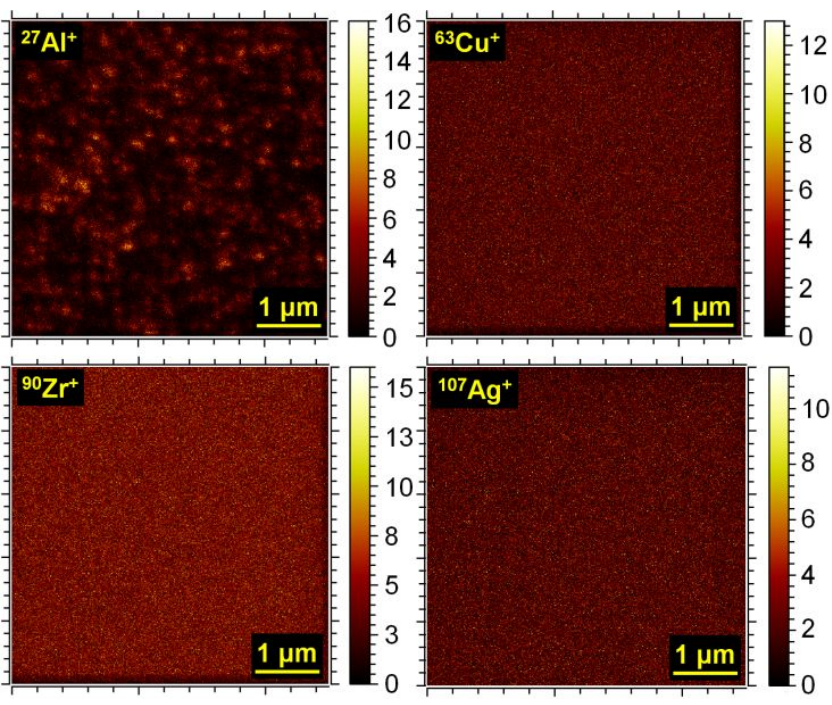

Figure 1. Elemental structure of $\mathrm{ZrCuAg}+\mathrm{Al}_{\text {np }}$ nanocomposite obtained with a $60 \mathrm{keV} \mathrm{Bi}_{3}{ }^{2+}$ beam (signal integration over 20 scans). No binning. a)

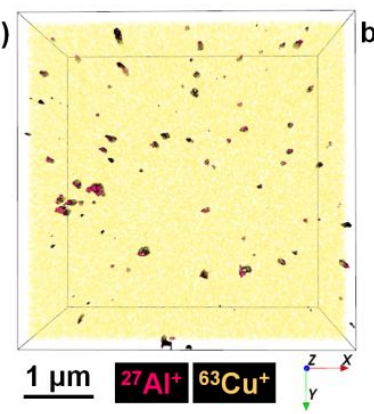

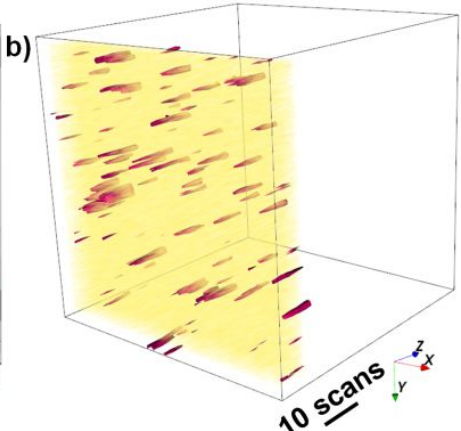

Figure 2. Overlay of ${ }^{27} \mathrm{Al}^{+}$signal (magenta) iso-surface (median filter with the kernel size $=3$ and the iso-value of $18.9 \%$ ) and ${ }^{63} \mathrm{Cu}^{+}$signal (yellow) measured with the TOF.SIMS ${ }^{5} . X y$ binning: 4 , binning in $z$ : 2, visualization over 9 scans. a) a front view, b) a side view. A $z$-axis is given in time units. The data was cropped in $z$ to visualize better the $\mathrm{Al}$ nanoparticles.

$\mathrm{Cu}, \mathrm{Zr}$ and $\mathrm{Ag}$ in not negligible. The depth of removed matter can be measured using in-situ (to prevent formation of an oxidized layer on the surface of crater bottom) AFM (Atomic Force Microscope) or in-situ SEM just after TOF-SIMS measurement but our setup was not equipped in any of these.

The TOF-SIMS measurements were repeated with a $30 \mathrm{keV}$ continuous $\mathrm{Ga}^{+}$beam at similar experimental conditions. Although the Al nanoparticles are not as distinct as in the previous case, the data (Figure 3) is comparable.

The detection of nanoparticles and the capability of resolving them spatially in 3D using different incident beams $\left(\mathrm{Bi}_{3}{ }^{2+}\right.$ and $\mathrm{Ga}^{+}$) during the TOF-SIMS analysis is a great achievement and was achieved for the first time. The stronger TOF-SIMS signals and therefore better resolution of images were obtained using $\mathrm{Bi}_{3}{ }^{2+}$ primary ion beam although according to the manufacturers' specifications the best lateral resolutions of both instruments are similar and can be as high as $50-60 \mathrm{~nm}$. Moreover, in this case, the sample ROI was exposed to more than 40 times lower dose than during the 

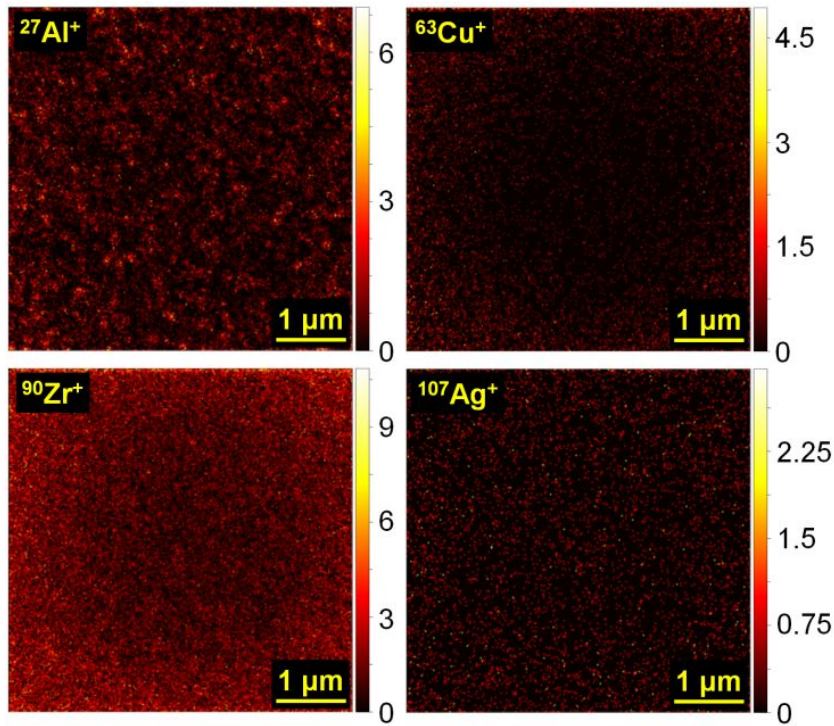

Figure 3. Elemental structure of $\mathrm{ZrCuAg}+\mathrm{Al}_{\text {np }}$ nanocomposite obtained with a $30 \mathrm{keV} \mathrm{Ga}{ }^{+}$beam (signal integration over 190 scans).
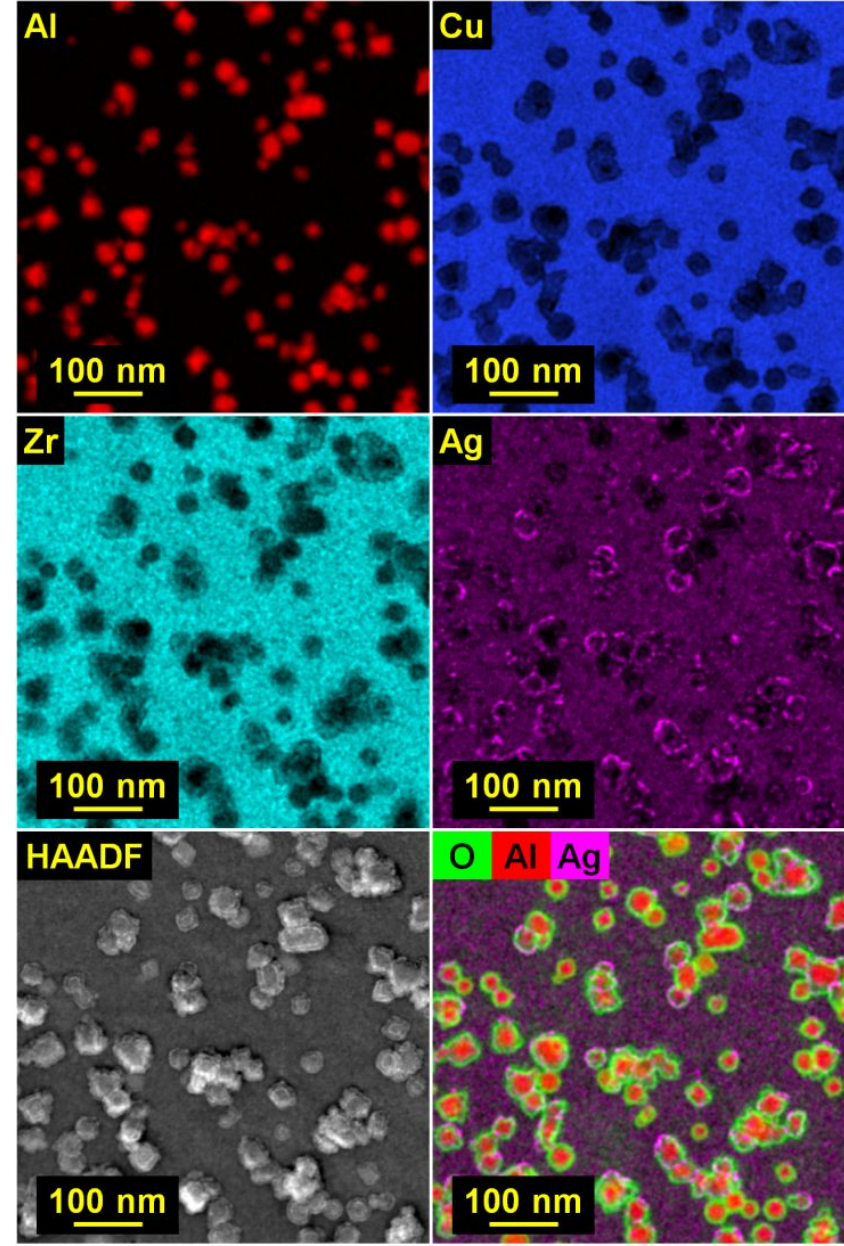

Figure 4. STEM-HAADF and STEM-EDX (at \%) images of a 50 $\mathrm{nm}$ thick layer of $\mathrm{ZrCuAg}+\mathrm{Al}_{\text {np }}$. In the colour maps, the scale is such that the quantity of material increases in tone from black (the lowest values) to the given colour (the highest values). experiment with $\mathrm{Ga}^{+}$. There are several factors that have determined the final quality of the TOF-SIMS images. First of all, the measurements performed with $\mathrm{Bi}_{3}{ }^{2+}$ were accompanied by a simultaneous delivery of oxygen to the sample surface which most likely has significantly enhanced the positive ion yields. Secondly, the sputtering yields $Y_{S}$, defined as a number of all ejected species (i.e. atoms, molecules or ions) from a target per impinging primary ion ${ }^{27}$, for both experiments were different due to the type and energy $E$ of primary ions as well as an incident angle $\alpha$. The roughly estimated Al sputter yields based on Yamamura model ${ }^{48-51}$ (the data is provided in SurfaceLab 6.5 software from IONTOF) are $Y_{S B i}=48.76$ (at $E_{B i}=60 \mathrm{keV}$ and $\alpha_{-B i}=45^{\circ}$ ) and $Y_{S_{-} G a}=4.69$ (at $E_{-G a}=30$ $\mathrm{keV}$ and a normal incidence). This already introduces a difference in the sputtering efficiency by a factor of 10 but the actual value can be even greater since other experiments and molecular dynamic simulations showed that the sputter yields of poly-atomic $\mathrm{Bi}\left(\mathrm{Bi}_{3}\right.$ and $\left.\mathrm{Bi}_{5}\right)$ beams are higher than those obtained with $\mathrm{Bi}_{1}{ }^{52,53}$. Also in the case of CTOF the extraction optics is not optimal because of the fact that the CTOF detector is built to adapt to an existing FIB-SEM system (whilst TOF.SIMS ${ }^{5}$ is a standalone dedicated instrument) and the available space in a vacuum chamber is limited. Finally, the difference in image quality given in Figure 1 and Figure 3 can be explained by higher secondary ion yields that are determined by the greater mass and the energy of primary ions (mass of $\mathrm{Ga}^{+}=69 \mathrm{u}$, mass of $\mathrm{Bi}_{3}{ }^{2+}=267 \mathrm{u}$, energy of $\mathrm{Ga}^{+}=30$ $\mathrm{keV}$, energy of $\mathrm{Bi}_{3}{ }^{2+}=60 \mathrm{keV}$ ). Moreover, applying heavy polyatomic projectiles has an advantage over monoatomic beams as it allows the ion formation efficiency to be maximized due to the uniform energy transfer that occurs in a near surface region ${ }^{45,54,55}$.

TEM and EDX measurements of nanoparticle size and nanocomposite structure

As mentioned, the size and shape of nano-objects obtained with TOF-SIMS can be affected by the imaging beam. Therefore, in order to validate the acquired data and precisely measure the size of Al nanoparticles, supplementary TEM measurements were performed in scanning mode on a $50 \mathrm{~nm}$ thick $\mathrm{ZrCuAg}+\mathrm{Al}_{\text {np }}$ thin film. The elemental structure of the sample was characterized with the EDX technique. Figure 4 shows the irregular distribution of nanoparticles that are composed of a pure aluminum core and an oxygen-silver shell. The presence of oxygen shell can have beneficial effect on $\mathrm{Al}$ ionization efficiency during the TOF-SIMS measurements as oxygen is a well-known element for enhancing positive ion yields. The size of isolated nanoparticles varies between 25 $\mathrm{nm}$ and $64 \mathrm{~nm}$ but they regularly form up to $175 \mathrm{~nm}$ large agglomerates/clusters. Moreover, $\mathrm{Al}$ is strictly confined within nanoparticles and no diffusion towards the BMG matrix was observed. The uniform distribution of the matrix elements $(\mathrm{Cu}$, $\mathrm{Zr}$ and $\mathrm{Ag}$ ) between the $\mathrm{Al}$ nanoparticles is consistent with the TOF-SIMS data. However, in contrast to Figure 1 and Figure 3 , lower matrix signals at the locations of $\mathrm{Al}$ nanoparticles and a higher Ag signal around $\mathrm{Al}$ nanoparticles can be discriminated. 
Lower limit for a nanoparticle size measured with TOFSIMS

In this section we try to estimate a minimum size of $\mathrm{Al}$ nanoparticles that can be measured. The amount of matter, $n$, given in moles can be defined as

$$
n=\frac{N}{N_{A}}
$$

where $N$ is a total number of atoms and $N_{A=} 6.02 \cdot 10^{23} \mathrm{~mol}^{-1}$ is the Avogadro constant.

The amount of matter can be also calculated as a ratio of a substance mass, $m$, and its molar mass, $\mu$ :

$$
n=\frac{m}{\mu}
$$

Combining Equation (1) and Equation (2) and assuming that all $\mathrm{Al}$ atoms are confined within a spherical volume (therefore $V=4 / 3 \pi r_{n p}{ }^{3}$, where $r_{n p}$ is the radius of a nanoparticle) this leads to

$$
r_{n p}=\sqrt[3]{\frac{3}{4 \pi N_{A}} \cdot \frac{\mu N}{\rho}}
$$

However, not all sputtered atoms, $N_{A S}$ (here $N=N_{A S}$ ), are ionized and can be guided towards a mass spectrometer, and thus be measured. In order to calculate the number of detected ions $N_{I D}$, an element useful yield, $Y_{\text {useful }}$, defined as

$$
Y_{\text {useful }}=\frac{N_{I D}}{N_{A S}}
$$

must be known. Since the value of $Y_{\text {useful }}$ depends not only on the element ionization probability but also on instrumental parameters and a detector type ${ }^{54-56}$, we have calculated the $\mathrm{Al}$ useful yield based on a TOF-SIMS depth profile measurement of $100 \mathrm{~nm}$ pure $\mathrm{Al}$ thin film deposited with the PVD technique on a $\mathrm{Si}$ wafer. A total of $9.8 \cdot 10^{7}{ }^{27} \mathrm{Al}^{+}$ions were detected. Knowing the sputtered volume $V_{S}=2.5 \mu \mathrm{m} \times 2.5 \mu \mathrm{m} \times 100$ $\mathrm{nm}=625 \cdot 10^{-21} \mathrm{~m}^{3}$, the Al bulk density $\rho_{A l}=2700 \mathrm{~kg} \cdot \mathrm{m}^{-3}$, the $\mathrm{Al}$ useful yields of $2.60 \cdot 10^{-3}$ was obtained.

Combining Equation (3) and Equation (4), finally we obtain:

$$
r_{n p}=\sqrt[3]{\frac{3}{4 \pi N_{A}} \cdot \frac{\mu N_{I D}}{\rho Y_{\text {useful }}}}
$$

Knowing that $\mathrm{Al}$ molar mass, $\mu_{A l}$, is $26.98 \cdot 10^{-3} \mathrm{~kg} \cdot \mathrm{mol}^{-1}$, assuming no mass-interference with other elements, no significant matrix effect, a negligible low noise level, complete confinement of a nanoparticle within a voxel sputtered by a primary ion beam and an extreme value of $N_{I D}=$ 1 (meaning that only 1 ion is sufficient for TOF-SIMS), the minimum size (diameter $d_{n p}=2 \cdot r_{n p}$ ) of a nanoparticle detectable with TOF-SIMS was estimated to be $2.3 \mathrm{~nm}$. Considering that, due to the noise level, the detection limit is 10,100 or even $1000 \mathrm{Al}$ ions, the sizes of nanoparticles have to be about $d_{n p_{-} 10}=5 \mathrm{~nm}, d_{n p_{-} 100}=11 \mathrm{~nm}$ and $d_{n p_{-} 1000}=23 \mathrm{~nm}$, respectively.

In summary, taking into account the TEM results and assuming the distance between nanoparticles to be large enough, the presented considerations suggest that the TOFSIMS technique has the capability to detect and spatially resolve single Al nanoparticles. However, due to the primary beam size, the TOF-SIMS measurements can overestimate the real size of nanoparticles.

\section{CONCLUSIONS}

In conclusion, for the first time we have demonstrated that tens of nanometres large metallic nanoparticles can be spatially resolved in inorganic nanocomposites using the TOFSIMS technique. This can be achieved when ion yields are sufficiently high, an appropriate combination of components preventing a mass-interference between a nanoparticle element and matrix elements is provided, sputtering rates of nanoparticles and a matrix are comparable, the distance between nanoparticles is greater than the size of the primary ion beam and the instrument has a low detection limit. However, the capability of the TOF-SIMS technique for measuring the nanoparticle size is mainly constrained by the imaging beam size. Additionally, blurring of the imaged nanoobject boundaries can occur due to interactions with the matrix components. Therefore, in order to assess the actual size of $\mathrm{Al}$ nanoparticles and validate the obtained TOF-SIMS results the TEM imaging was performed.

Nevertheless, TOF-SIMS technique provides information on elemental structure at the nano- and micro-scales, ensuring better statistics which is a requirement for designing new functional materials as well as monitoring the quality of the fabrication process (both locally and globally). For example the BMG based nanocomposite presented in this paper is expected to find an application in medicine (for instance in producing endoprostheses). In order to maximize their performance (mechanical properties, reducing crack propagation and development of shear bands) the processes such as material segregation, surface oxidation (including oxidation of nanoparticle surfaces during the fabrication), presence of contaminants and element diffusion have to be profoundly understood.

\section{AUTHOR INFORMATION}

\section{Corresponding Author}

*Agnieszka.priebe@empa.ch

\section{Author Contributions}

The manuscript was written through contributions of all authors. / All authors have given approval to the final version of the manuscript.

\section{ACKNOWLEDGMENT}

This project has received funding from the EU-H2020 research and innovation programme under grant agreement No 654360 having benefitted from the access provided by CEA-LETI in Grenoble (France) within the framework of the NFFA-Europe Transnational Access Activity. The EMPAPOSTDOCS-II programme has received funding from the European Union's Horizon 2020 research and innovation programme under the Marie Skłodowska-Curie grant agreement number 754364.

\section{REFERENCES}

(1) Ajayan, P. M.; Schadler, L. S.; Braun, P. V. 
Nanocomposite Science and Technology; Wiley-VCH Verlag GmbH \& Co. KGaA: Weinheim, 2003.

(2) Thostenson, E. T.; Li, C.; Chou, T. W. Nanocomposites in Context. Compos. Sci. Technol. 2005, 65 (3-4), 491-516.

(3) Wang, W. H.; Dong, C.; Shek, C. H. Bulk Metallic Glasses. Mater. Sci. Eng. R Reports 2004, 44 (2-3), 45-90.

(4) Löffler, J. F. Bulk Metallic Glasses. Intermetallics 2003, 11 (6), 529-540

(5) Axinte, E. Metallic Glasses from "Alchemy" to Pure Science: Present and Future of Design, Processing and Applications of Glassy Metals. Mater. Des. 2012, 35, 518-556.

(6) Wang, W. H. The Elastic Properties, Elastic Models and Elastic Perspectives of Metallic Glasses. Prog. Mater. Sci. 2012, 57 (3), 487-656.

(7) Trexler, M. M.; Thadhani, N. N. Mechanical Properties of Bulk Metallic Glasses. Prog. Mater. Sci. 2010, 55 (8), 759-839.

(8) Greer, A. L.; Cheng, Y. Q.; Ma, E. Shear Bands in Metallic Glasses. Mater. Sci. Eng. R Reports 2013, 74 (4), 71-132.

(9) Hufnagel, T. C.; Schuh, C. A.; Falk, M. L. Deformation of Metallic Glasses: Recent Developments in Theory, Simulations, and Experiments. Acta Mater. 2016, 109, 375-393.

(10) Hosokawa, M.; Nogi, K.; Naito, M.; Yokoyama, T. Nanoparticle Technology Handbook; 2012.

(11) Miller, M. K. Atom Probe Tomography Analysis at the Atomic Level; Springer US, 2000.

(12) Miller, M. k.; Kenik, E. a. Atom Probe Tomography: A Technique for Nanoscale Characterization. Microsc. Microanal. 2004, 10 (03), 336-341.

(13) Miller, M. K.; Forbes, R. G. Atom-Probe Tomography: The Local Electrode Atom Probe; 2014.

(14) Kelly, T.; Miller, M. Atom Probe Tomography. Rev. Sci. Instrum. 2007.

(15) Kelly, T. F.; Miller, M. K. Invited Review Article: Atom Probe Tomography. Rev. Sci. Instrum. 2007, 78 (3), 031101-1031101-20.

(16) Williams, D. B.; Carter, C. B. The Transmission Electron Microscope. In Transmission Electron Microscopy; 1996.

(17) Reimer, L.; Kohl, H. Transmission Electron Microscopy Physics of Image Formation; 2008.

(18) Gault, B.; Moody, M. P.; De Geuser, F.; La Fontaine, A.; Stephenson, L. T.; Haley, D.; Ringer, S. P. Spatial Resolution in Atom Probe Tomography. Microsc. Microanal. 2010, 16 (01), 99 110 .

(19) Smith, D. J. Ultimate Resolution in the Electron Microscope? Mater. Today 2008, 11 (SUPPL.), 30-38.

(20) Smith, D. J. Progress \& Perspectives for AtomicResolution Electron Microscopy. Mater. Today 2009, 12 (SUPPL.), $10-16$.

(21) Vogt, T.; Dahmen, W.; Peter, B. Modeling Nanoscale Imaging in Electron Microscopy; Springer Science+Business: New York, 2012

(22) Miller, M. K.; Russell, K. F.; Thompson, K.; Alvis, R.; Larson, D. J. Review of Atom Probe FIB-Based Specimen Preparation Methods. Microsc. Microanal. 2007, 428-436.

(23) Giannuzzi, L. A.; Stevie, F. A. A Review of Focused Ion Beam Milling Techniques for TEM Specimen Preparation. Micron 1999, 30 (3), 197-204.

(24) Langford, R. M.; Rogers, M. In Situ Lift-out: Steps to Improve Yield and a Comparison with Other FIB TEM Sample Preparation Techniques. Micron 2008, 39 (8), 1325-1330.

(25) Mayer, J.; Giannuzzi, L. a; Kamino, T.; Michael, J. TEM Sample Preparation and Damage. MRS Bull. 2007, 32 (5), 400-407.

(26) Benninghoven, A.; Werner, F. G.; W., R. and H. Secondary Ion Mass Spectrometry-basic Concepts, Instrumental Aspects, Applications and Trends. Surf. Interface Anal. 1987, 10 (8), 435.

(27) Van de Heide, P. Secondary Ion Mass Spectrometry: An Introduction to Principles and Practices; Wiley, 2014.
(28) Kollmer, F.; Paul, W.; Krehl, M.; Niehuis, E. Ultra High Spatial Resolution SIMS with Cluster Ions - Approaching the Physical Limits. Surf. Interface Anal. 2013, 45 (1), 312-314.

(29) Alberts, D.; Von Werra, L.; Oestlund, F.; Rohner, U.; Hohl, M.; Michler, J.; Whitby, J. A. Design and Performance of Two Orthogonal Extraction Time-of-Flight Secondary Ion Mass Spectrometers for Focused Ion Beam Instruments. Instrum. Sci. Technol. 2014, 42 (4), 432-445.

(30) https://www.iontof.com/tof-sims-secondary-ion-massspectrometry.html.

(31) Hawkes, P. W.; Spence, J. C. H. Science of Microscopy; Springer Science \& Business Media: New York, 2008.

(32) Priebe, A.; Goret, G.; Bleuet, P.; Audoit, G.; Laurencin, J.; Barnes, J. P. 3D Correlative Morphological and Elemental Characterization of Materials at the Deep Submicrometre Scale. $J$. Microsc. 2016, 264 (2), 247-251.

(33) Lee, J. L. S.; Gilmore, I. S.; Fletcher, I. W.; Seah, M. P. Topography and Field Effects in the Quantitative Analysis of Conductive Surfaces Using ToF-SIMS. Appl. Surf. Sci. 2008, 255 (4), $1560-1563$.

(34) Rangarajan, S.; Tyler, B. J. Topography in Secondary Ion Mass Spectroscopy Images. J. Vac. Sci. Technol. A Vacuum, Surfaces, Film. 2006, 24 (5), 1730-1736.

(35) Priebe, A.; Audoit, G.; Barnes, J. P. A Novel PFIB Sample Preparation Protocol for Correlative 3D X-Ray CNT and FIB-TOFSIMS Tomography. Ultramicroscopy 2017, 173, 10-13.

(36) Alberts, D.; von Werra, L.; Oestlund, F.; Rohner, U.; Hohl, M.; Michler, J.; Whitby, J. A. Design and Performance of Two Orthogonal Extraction Time-of-Flight Secondary Ion Mass Spectrometers for Focused Ion Beam Instruments. Instrum. Sci. Technol. 2014, 42 (4), 432-445.

(37) Whitby, J. A.; Östlund, F.; Horvath, P.; Gabureac, M.; Riesterer, J. L.; Utke, I.; Hohl, M.; Sedláček, L.; Jiruše, J.; Friedli, V.; et al. High Spatial Resolution Time-of-Flight Secondary Ion Mass Spectrometry for the Masses: A Novel Orthogonal ToF FIB-SIMS Instrument with in Situ AFM. Adv. Mater. Sci. Eng. 2012, 2012, 113.

(38) Senoner, M.; Wirth, T.; Unger, W. E. S. Imaging Surface Analysis: Lateral Resolution and Its Relation to Contrast and Noise. $J$. Anal. At. Spectrom. 2010, 25 (9), 1440-1452.

(39) Henss, A.; Otto, S.-K.; Schaepe, K.; Pauksch, L.; Lips, K. S.; Rohnke, M. High Resolution Imaging and 3D Analysis of Ag Nanoparticles in Cells with ToF-SIMS and Delayed Extraction. Biointerphases 2018, 13 (3), 03B410.

(40) Benettoni, P.; Stryhanyuk, H.; Wagner, S.; Kollmer, F.; Moreno Osorio, J. H.; Schmidt, M.; Reemtsma, T.; Richnow, H.-H. Identification of Nanoparticles and Their Localization in Algal Biofilm by 3D-Imaging Secondary Ion Mass Spectrometry. J. Anal. At. Spectrom. 2019.

(41) Graham, D. J.; Wilson, J. T.; Lai, J. J.; Stayton, P. S.; Castner, D. G. Three-Dimensional Localization of Polymer Nanoparticles in Cells Using ToF-SIMS. Biointerphases 2015, 11 (2), $02 \mathrm{~A} 304$.

(42) Benninghoven, A. Chemical Analysis of Inorganic and Organic Surfaces and Thin Films by Static Time-of-Flight Secondary Ion Mass Spectrometry (TOF-SIMS). ChemInform 1994, No. 33, 1023 .

(43) Sree Harsha, K. S. Principles of Vapor Deposition of Thin Films; Elsevier Ltd, 2006.

(44) Priebe, A.; Bleuet, P.; Goret, G.; Laurencin, J.; Montinaro, D.; Barnes, J.-P. State-of-the-Art Three-Dimensional Chemical Characterization of Solid Oxide Fuel Cell Using Focused Ion Beam Time-of-Flight Secondary Ion Mass Spectrometry Tomography. Microsc. Microanal. 2016, 22, 1261-1269.

(45) Vickermann, J. C.; Briggs, D. ToF-SIMS: Materials Analysis by Mass Spectrometry, 2nd ed.; IM Publications LLP: West Sussex, United Kingdom, 2013. 
(46) Fleck, R. A.; Humbel, B. M. Biological Field Emission Scanning Electron Microscopy; John Wiley \& Sons, INC.: West Sussex, United Kingdom, 2019.

(47) Orsay Physics. Technical Sheet of "Cobra The wellrecognized Ga FIB column" http://www.orsayphysics.com/upload/1466673230.pdf (accessed Mar 19, 2019).

(48) Matsunami, N.; Yamamura, Y.; Itikawa, Y.; Itoh, N.; Kazumata, Y.; Miyagawa, S.; Morita, K.; Shimizu, R.; Tawara, H. Energy Dependence of the Ion-Induced Sputtering Yields of Monatomic Solids. At. Data Nucl. Data Tables 1984, 31 (1), 1-80.

(49) Yamamura, Y.; Tawara, H. Yamamura \& Tawara (1996) Energy Dependence of Ion-Induced Sputtering Yields from Monatomic Solids at Normal Incidence.Pdf. At. Data Nucl. Data Tables 1996, 62 (0005), 149-253.

(50) Yamamura, Y.; Mössner, C.; Oechsner, H. The Bombarding-Angle Dependence of Sputtering Yields under Various Surface Conditions. Radiat. Eff. 1987, 103 (1-4), 25-43.

(51) Yamamura, Y.; Itikawa, Y.; Itoh, N. Angular Dependence of Sputtering Yields of Monatomic Solids. Inst. Plasma Physics, Nagoya Univ. 1983, IPPJ-AM-26.

(52) Muramoto, S.; Brison, J.; Castner, D. G. Exploring the Surface Sensitivity of ToF-SIMS by Measuring the Implantation and Sampling Depths of Bin and C60 Ions in Organic Films. Anal. Chem. 2012, 84, 365-372.

(53) Delcorte, A.; Leblanc, C.; Poleunis, C.; Hamraoui, K. Computer Simulations of the Sputtering of Metallic, Organic, and Metal-Organic Surfaces with Binand C60projectiles. J. Phys. Chem. C 2013, 117 (6), 2740-2752.

(54) Kollmer, F. Cluster Primary Ion Bombardment of Organic Materials. Appl. Surf. Sci. 2004, 231-232, 153-158.

(55) Weibel, D.; Wong, S.; Lockyer, N.; Blenkinsopp, P.; Hill, R.; Vickerman, J. C. A C60primary Ion Beam System for Time of Flight Secondary Ion Mass Spectrometry: Its Development and Secondary Ion Yield Characteristics. Anal. Chem. 2003, 75 (7), 17541764.

(56) Pillatsch, L.; Wirtz, T. SIMS Using O -, F -, Cl -, Br - and I - Primary Ion Bombardment. Surf. Interface Anal. 2012, 44 (10), 1370-1372. 